\title{
Navigating Process-Product Tensions using a Design Canvas
}

\section{Dr. R. Alan Cheville, Bucknell University}

Alan Cheville studied optoelectronics and ultrafast optics at Rice University, followed by 14 years as a faculty member at Oklahoma State University working on terahertz frequencies and engineering education. While at Oklahoma State, he developed courses in photonics and engineering design. After serving for two and a half years as a program director in engineering education at the National Science Foundation, he took a chair position in electrical engineering at Bucknell University. He is currently interested in engineering design education, engineering education policy, and the philosophy of engineering education.

\section{Prof. Michael S. Thompson, Bucknell University}

Prof. Thompson is an associate professor in the department of Electrical and Computer Engineering at Bucknell University, in Lewisburg, PA. While his teaching responsibilities typically include digital design, computer-related electives, and senior design, his focus in the classroom is to ignite passion in his students for engineering and design through his own enthusiasm, open-ended projects, and connecting engineering to the world around them. His research tends to focus on the application of mobile computing to a variety of non-technical problems. He holds three degrees in computer engineering including a B.S. from North Carolina State University and an M.S. and Ph.D. from Virginia Tech. 


\title{
Navigating Process-Product Tensions using a Design Canvas
}

\begin{abstract}
National surveys of design courses find many similarities between the way capstone courses are structured and implemented, although more programs focus on the design process rather than creating a product. What is not as well understood are the methods and techniques used to inform students of interrelationship between product and process. This paper discusses the use of multiple formal design representations as a means to focus learning on the interrelation between design processes and products. The ability to utilize multiple representations has been demonstrated to be effective in improving student learning in math education, a discipline that can be highly process-oriented. Similarly representational fluency impacts engineering modeling. In the context of teaching design the term representation here refers to a written or graphical expression of some aspect of the design process and/or product. Ideally the set of representations would form a minimal and complete orthonormal basis set; that is the ensemble of representations captures the design in its entirety and the representations are not redundant. Since the design work of many engineers is a set of plans or diagrams (forms of representation) the complete set of representations has the potential to capture both the process of design and serve as a product of design work. Over a four year period a set of representations was developed and trialed in a year-long senior capstone course in electrical and computer engineering at a small, private liberal arts institution. Using an iterative, action research approach that included student input a set of representations was developed by modifying or eliminating ineffective representations and introducing new formats based on analysis of the students' response and success. To minimize redundancy and work towards completeness (i.e. a lean, $360^{\circ}$ view of the process and product) representations were organized using a "design canvas" modeled after the Business Model Canvas. The Design Canvas classifies representations by actionable questions on two axes - system development and design choiceswhich in turn are organized hierarchically by scale. Results of the project and examples of representations for the current iteration of the Design Canvas are presented along with the Design Canvas development process.
\end{abstract}

\section{Product, Process and Representations in Capstone Design?}

Looking at the range of capstone design courses show that there is a wide variation of approaches in balancing the importance of design product vs. design process. A 2015 survey [1] indicates that while about three times as many courses emphasize process as do product, the majority of courses seek to balance the result of the capstone experience (product) with the planned actions that led to that result (process). Respondents indicated that process and product are tightly coupled. An earlier national survey found that assessment was most closely tied to the product produced in capstone courses [2] and oftentimes clients are asked to evaluate products [3]. The focus on product vs. process also varies across disciplines since fabrication of a final product can be difficult or cost-prohibitive in disciplines such as civil engineering [4]. 
Some authors argue that focusing on process is needed if students are to improve as designers [5]. Others emphasize that design is more than the sum of individual designer's products [6] since the process of design is inherently social. This paper discusses a multi-year effort to more tightly integrate process and product by focusing on design representations, or artifacts, that capture process and also serve as part of the product of a design course.

Design representations are an integral element of the design process that have been tied to design creativity [7] and process [8]. Representations are also important in education in both math and chemistry [9] and have been shown to relate to how well engineering students can create models [10]. At a more fundamental level representations are integral to engineering design and help to distinguish engineering from science. As Basset and Krupczak [11] have pointed out science seeks to produce theory by abstracting from specific observations. Engineers on the other hand need to understand the abstracted theory but also reverse the vector of abstraction to move from broad principles to specific, contextualized objects or processes that meet human needs:

"The process of devising a solution involves creating an object that produces needed outputs from the required, desired, or available inputs. In order to create such an object, an engineer must have a prior conception of how function is related to the physical or technological structure of objects. In addition, insofar as overall function is a compilation of subfunctions, and insofar as the overall structure of the object is a compilation of its components, an engineer must be able to grasp these relations, so that the inputs and outputs of each component or subfunction match at each component interface. The conceptual design phase may even explore alternative configurations of subfunctions as well as alternative choices for the types of components to achieve those subfunctions. Thus, the design process requires an understanding of the relationship of function and structure, and of the relationship of whole and parts, abstracted from the particular case." [11]

Not only do the functions of a design have to match but for more complex projects, such as given in capstone courses, engineering design is a distributed process in that it involves multiple parties each with different interests. These parties each have some specific and general interests which go back and forth along the vector of abstraction through negotiation and other social interactions. Design representations play a significant role in these negotiations since they act as "centers of conversation" where such social interactions take place and thus support two way movement along the vector of abstraction [6], [12]. Representation thus serves as elements or markers of the inherently social design process, but also serve as products that capture that process. Ideally representations communicate the product on a variety of levels to a variety of stakeholders, but also are dynamic in that they change over time as design is negotiated. These changes over time - captured in the representations - can give insights to the process of design that leads to a product. 


\section{Context for Design Representations}

The representations discussed in this paper were created in the first semester of a year-long capstone design course required for electrical and computer engineering students in their final undergraduate year. The course utilizes externally-sponsored projects by teams of mixed electrical and computer engineers. The course is divided into twelve design milestones each with a set of deliverables; there are six milestones in the first semester and six in the second. The deliverables in the first semester focuses on creating design representations which capture the design process while those in the second semester focus on creating product deliverables. This division between product and process is deliberate and designed to roughly follow a generalized "V-model" for systems development [13], figure 1.

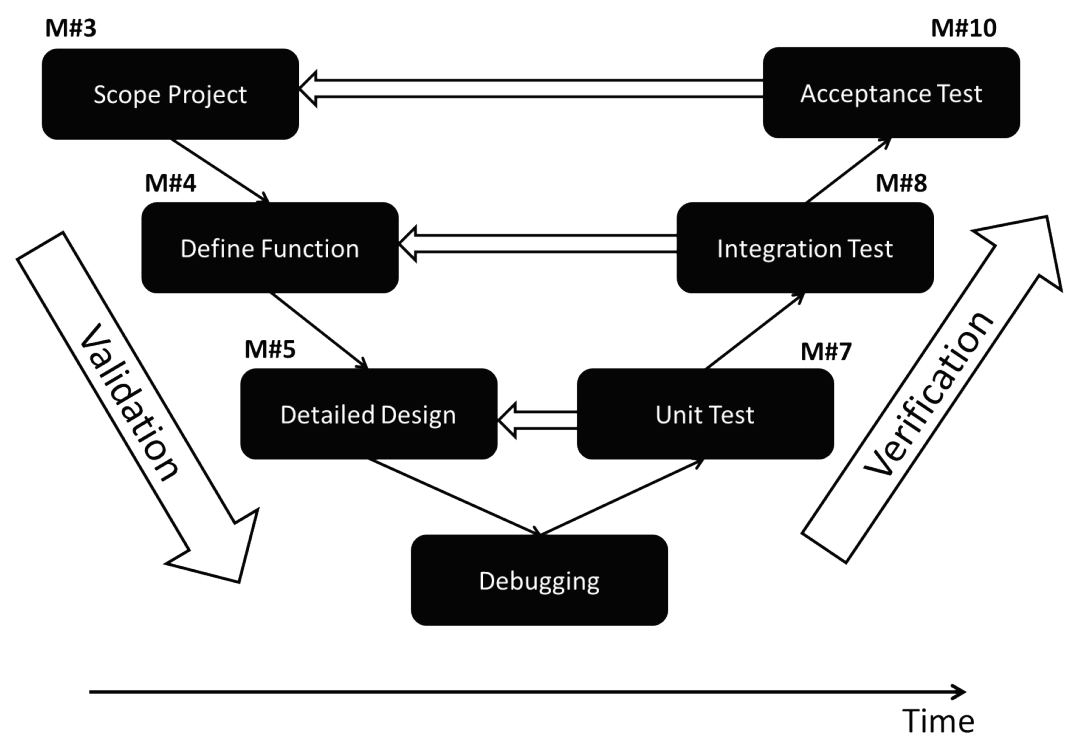

Figure 1: Representation of the V-model on which the capstone class is loosely based.

The V-model has two phases, validation on the left and verification on the right. The validation phase focuses on effectiveness, do the design decisions reflect the right thing to do, while the verification phase focuses on efficiency or whether the planned design is being executed the right way. The top of the Vee represents broader more contextual elements of design while the bottom of the Vee represents detailed design. In this model as student teams move from left to right through the design course they first represent their design in increasing levels of detail then execute their design at the subsystem level then integrate and iterate at the system level before determining if the design meets the broad requirements. Tests at each stage of the verification phase are matched back to requirements determined in the validation phase. Note that while the $\mathrm{V}$-model provides an intuitive framework for design, rigidly applying it with novice designers is not recommended since it assumes a certain level of familiarity with design, the ability to predict outcomes to some degree, and is more useful for managing a project than for learning engineering design. 
The course from which results are reported has been iterated over time using an action research approach [14]. Action research engages the researcher as well as other in improving or iterating upon the actions taken in a given scenario. In this case the scenario is improving outcomes in the capstone design course which is supported by underlying theories of social development in education pioneered by Lev Vygotsky and instantiated in the course through Rom Harre's Vygotsky Cycle [15], [16]. In brief this theory posits that a student's understanding develops through four sequential transitions: appropriation or getting information, transformation or internalizing that information, publication or reiterating that knowledge to others in a social environment, and conventionalization or integrating that knowledge into existing schemas. Students, as participants in the class, were engaged in design as a social process through: 1) regular meetings with the team project managers, 2) interactive end-of-semester after-action reviews, and 3) written reflections several times during the course. Over several years of collecting data and taking informed action it became clear that students were relatively prepared for, and capable in, the verification part of the V-model but struggled with validation. The feedback obtained from students can be summarized as a lack of clarity of the design process. For many students in the course this course is their first in-depth experience with engineering design and they often conflate designing with building. As novice designers [17] many do not see the importance of the validation phase of design since it seems disconnected from implementation and fabrication. Interestingly students expressed they want to be introduced to design in a holistic manner-that is understand the entire process before undertaking the project—but a lack of tacit knowledge [18] and experiences made it difficult to present such overviews in an effective manner.

To address these issues the authors went through several year-long cycles of acquiring faculty and student feedback, analysis, and making modifications to the course structure. Ideas were drawn broadly from other capstone courses [5], [12], [19]-[23] and an author's experience with the NSF ICorps-L program. Course changes were trialed at the author's institution, and implemented, adapted, or abandoned based on how effective they were at helping students understand the validation phase. Key metrics for whether an idea would be trialed in the course were:

1) how effective it was at shifting students focus from immediately jumping to project implementation and instead focusing on problem scoping,

2) whether it helped students gain understanding of the overall design process as evidenced by project planning, and

3) supporting students' understanding of the need for, and being able to conduct, effective research on possible solutions.

The instructors also noted that many students had difficulty in conceptualizing the structure or architecture of a project as separate from, but coupled with, the function and performance of the design. For this reason there was a particular focus on developing ways for students to capture and integrate the structure or architecture of a design as both separate from and related to the function of the design, particularly as related to performance. 


\section{Development of the Design Canvas.}

The multi-year process of action research described above converged on using multiple representations of the design process created by student teams as a product for the validation phase. Multiple representations are used in both math and design education to symbolize or describe a single entity in different ways [7]-[10]. The choice to use multiple representations to frame understanding during the validation phase of design is supported by the bidirectional vector of abstraction [11] in design since during validation it is necessary for students to quickly move back and forth - diverge and converge [5] - between the larger context of the problem and the specific forms of implementation. Representations are also a relatively easy way to incorporate multiple perspectives. As discussed subsequently most representations were required to be hand-drawn and thus were easily iterated. The physical artifact of a representation also serves as a "center of dialog" for teams to come around as various aspects of the design are negotiated [6], [12].

An open question was what representations would be effective for the goals listed previously, and what forms could/should the representations take? The authors also experimented with the number and organization of representations; e.g. should they be on a computer or hand-drawn, how many representations are too many, and what minimum set is sufficient to give a holistic overview of design? These issues emerged as critical issues through the action research process involving missteps, trial-and-error experiences, and student feedback during the development process of trying to operationalize design ideas into artifacts that could be created and iterated in the available time.

After several iterations representations were organized on to a "canvas", the space that constrains a painting. Canvases have been previously use in design [20] and entrepreneurship [24]. Such canvases map necessary elements of a creative process on to a two-dimensional space as a painter's canvas organizes a visual image. Many canvases capture elements of a creative process in the form of a palette, that is regions that correspond to different aspects of the process. In the design canvas presented here the authors chose a Cartesian framework with one axis based on system development or level of detail, and the other axis capturing choices made during the design process. Another way to view the canvas is that elements of the design process are mapped to columns and depth or level of detail of the design is mapped to rows. The authors made the choice to frame each row and column as a question rather than as a statement since the goal of the canvas is to map design representations to the information they provide in the design process. Time is not represented explicitly in the canvas but as discussed subsequently, the way topics are introduced in the sequence of design course occurs diagonally from left to right and up to down.

A simplified version of the canvas framing the overarching questions related to system development and choices in design is shown in Figure 2. As can be seen from the four rows of the canvas questions of system development go from the larger context of design to details about subsystems of the design. The five columns frame different aspects of the design process: 
project scoping, project function, project implementation, project testing, and project logistics. The complete version of the design canvas, Figure 3, provides more detail on each of the questions and maps specific design representations to the rows and columns. Each of the representations is briefly discussed and some of the failed attempts in earlier versions of the canvas are disclosed along with the reasons they did not work in the authors' capstone courses.

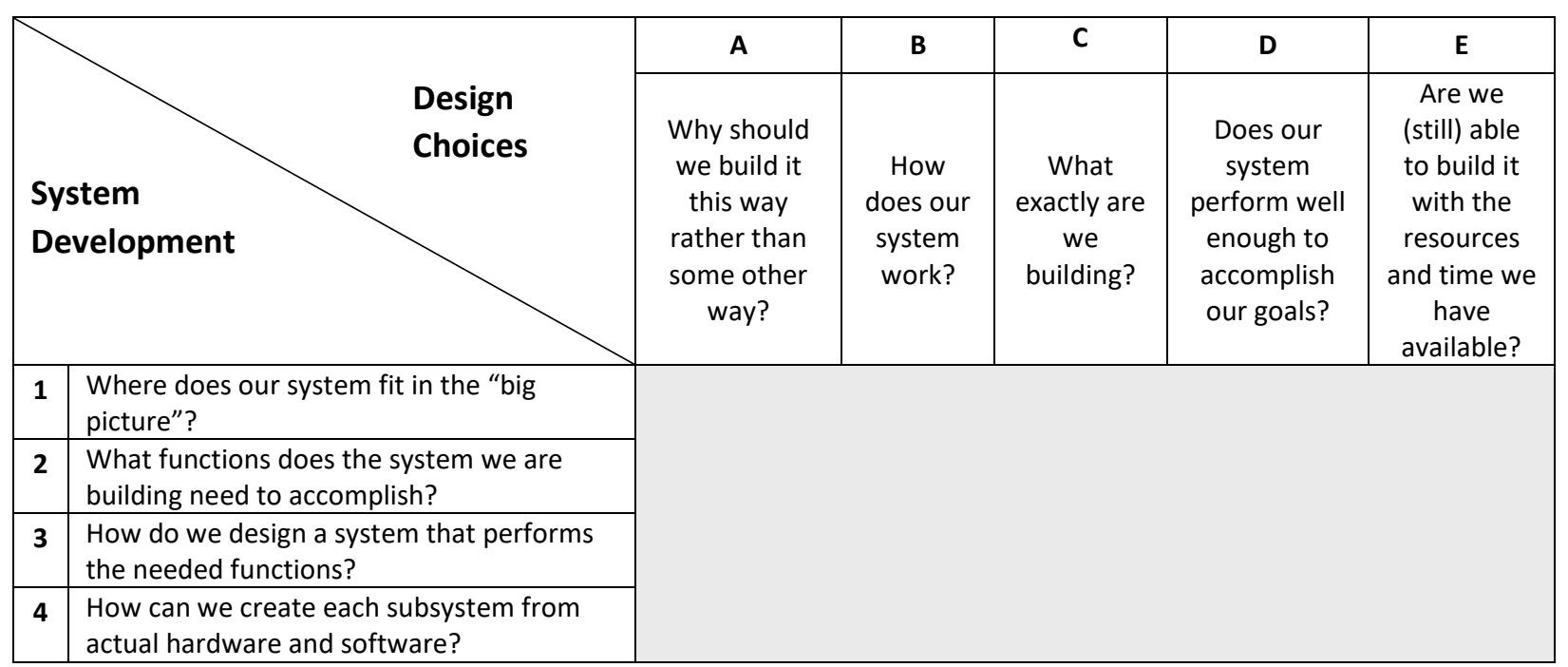

Figure 2: Simplified representation of the Design Canvas.

The representations mapped on the Design Canvas are referenced by the row (number) and column (letter) in the canvas.

Interviews, Stakeholder-Feature Model and Problem Definition (1:A-C): Problem identification and framing which require more divergent thinking issues are at the "big picture" level and cut across questions of what to build (A), how it functions (B), and system architecture (C). Earlier versions of the design canvas included story boards and use cases, but these were found to be too time consuming to teach and difficult for students to utilize well. Drawing from the lean start-up model [25] used in the NSF ICorps-L program student teams do sixty user interviews of the course of the systems by talking to potential users in the actual location their design will be used. Interviews are hypothesis-based [26] and students create interview protocols which start off with easy questions that engage the subject and end with requests for other contacts. The data obtained from interviews informs the stakeholder-feature model, a diagram that relates stakeholders to features they may desire and is used to help better understand the unique purpose or needs of your device to separate it from the larger classes of similar devices [19]. The stakeholder feature model is then expressed succinctly as a problem definition framed around the value the project will create for key stakeholder. The phrasing of the value proposition follows that used in ICorps-L: "Our (product or service) helps (specific users) who want to (accomplish some goal) by (phrase of what issue is solved or opportunity created) better than (competing approach)." 


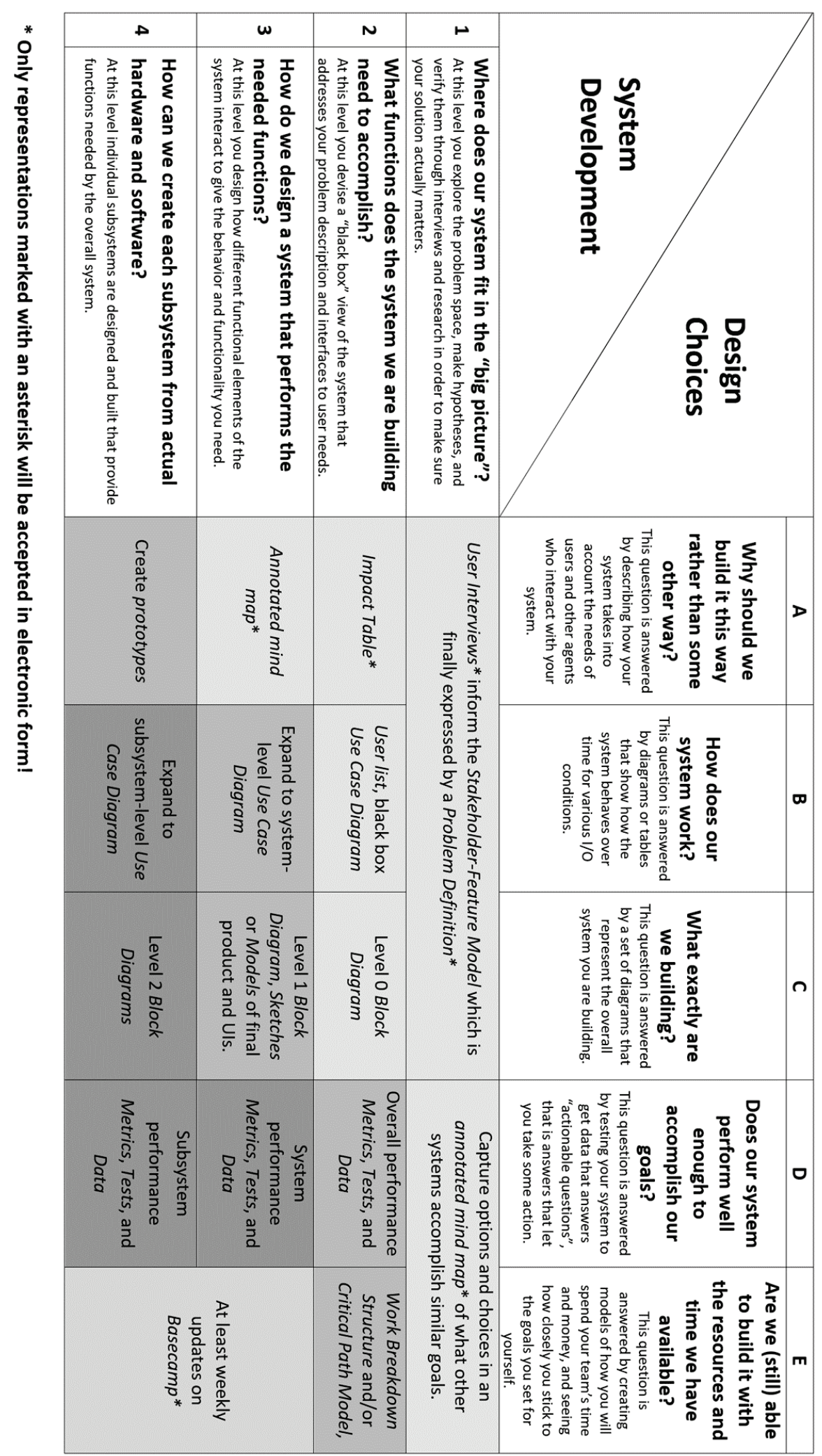

Figure 3: The full Design Canvas used to frame the validation semester of the capstone course. 
Impact Table (2:A): To contextualize the problem around factors such as public health, safety, manufacturability, etc. the students create an impact table which lists the contexts and constraints of the system [19]. Each context or constraint item includes a domain, the specific result of that item, a description, the impact direction (on the system or by the system), whether the impact is direct or indirect, and the perceived importance of the item as shown in Table 1. The impact table is designed to help students think through the specific constraints and contexts of their project and how it impacts and is impacted by larger societal factors and serves as a center of conversation [12] for the larger, societal aspects of the design.

Table 1: Format of the Impact Table Representation

\begin{tabular}{|l|l|l|l|l|l|}
\hline \multicolumn{1}{|c|}{ Domain } & \multicolumn{1}{|c|}{ Result of } & \multicolumn{1}{|c|}{ Description of Impact } & $\begin{array}{l}\text { Direction } \\
\text { affects / } \\
\text { affected by }\end{array}$ & $\begin{array}{l}\text { Degree } \\
\text { Direct / } \\
\text { Indirect }\end{array}$ & $\begin{array}{c}\text { Importance } \\
\text { Low/Med./High }\end{array}$ \\
\hline $\begin{array}{l}\text { Manufacture, } \\
\text { environment }\end{array}$ & $\begin{array}{l}\text { Must be water and dust } \\
\text { resistant and should be able } \\
\text { to withstand a large } \\
\text { temperature range }\end{array}$ & $\begin{array}{l}\text { System will be installed } \\
\text { outside in Austin, Texas. }\end{array}$ & $\begin{array}{l}\text { Affects } \\
\text { system }\end{array}$ & Direct & High \\
\hline $\begin{array}{l}\text { Social, } \\
\text { economic }\end{array}$ & $\begin{array}{l}\text { May reduce the number of } \\
\text { workers required }\end{array}$ & $\begin{array}{l}\text { Workers will be laid off, } \\
\text { money is saved }\end{array}$ & $\begin{array}{l}\text { Affected by } \\
\text { system }\end{array}$ & Indirect & Med. \\
\hline $\begin{array}{l}\text { Manufacture, } \\
\text { safety }\end{array}$ & $\begin{array}{l}\text { Cannot harm horse being } \\
\text { monitored }\end{array}$ & $\begin{array}{l}\text { Comfortable-to-wear } \\
\text { enclosure, should not } \\
\text { harm any of the horse's } \\
\text { senses }\end{array}$ & $\begin{array}{l}\text { Affects } \\
\text { system }\end{array}$ & Direct & High \\
\hline
\end{tabular}

Annotated Mind Map (3:A): To encourage students on a team to develop a common understanding of their design that is based on research, students were asked to build an electronic mind map annotated with citations and information. A mind map is a ball-and-stick form of diagram in which information is mapped through a series of interconnecting branches. Similar to those used for assessment mind maps which are useful for classifying ideas as student pursue divergent thinking, capturing what ideas have been explored, and also keeping track of which ideas have been eliminated from consideration. The students used an open source software tool, iMindQ, in which other information (links, files, etc.) can be inserted.

Create Prototypes (4:A): To represent form at the detailed level students created a prototype of their design out of readily available materials such as clay, cardboard, etc. The prototype was used to give the team a common reference for the design and obtain feedback from users and their client.

Use Case Diagrams (2-4:B): One of the more critical desired outcomes for the course was to get students to learn how frame design questions around issues of function and performance. Over several iterations of the course many different methods were attempted to create representations that were both approachable while also being effective at representing the behavior of a system; i.e. how the system input and output changed over time or as a result of changes in input. Early forms of representations had students abstract the functions by drawing from software representations to create flowcharts, sequence, timing, and activity diagrams. 
These types of abstractions were difficult for students to utilize effectively at early stages of the design process and the sheer number of diagrams required to capture function proved to be too much work to keep updated. Currently the course uses a modified use case diagram to represent behavior. Despite some initial confusion on the part of students this is an effective representation although more work is needed to clarify its purpose and function in design. Effectiveness is evidenced by the fact that as students get deeper into designs the use case diagrams become increasingly detailed and become more effective at explaining subsystem behavior.

Block Diagrams (2-4:C): The question of how a project is architected or the overall structure of the planned innovation are captured by level 0 to level 2 block diagrams. These diagrams abstract the key parts of a system as blocks (subsystems) and illustrate how these parts connect to each other (using lines) and to agents (entities external to the system). The details of the diagram vary by the level of abstraction where a Level 0 block diagram is one single box representing the system that focuses on how the agents interact with the system, a level 1 block diagram shows the interconnection of subsystems and what power or information flows between them, and a level 2 diagram will focus on how components within a given sub-system create the function of that sub-system. Blocks represent the part of the system that performs some function while the lines connecting blocks represent measureable information, power, or control. Since the block diagram represents how the project is structured, the blocks generally do not vary with time or input. Students are advised to think of block diagrams as a blueprint of how the system will be built which specifies modules, components, and code.

Block diagrams are typically focused on the hardware aspects of the project with software being represented as sub-blocks which are executed on computing blocks - for example, a microcontroller may be a block at level 1 and the program that runs on it is shown in level 2. Students often do not clearly separate of hardware and software in these diagrams unless prompted to do so. Through iteration it was discovered that asking that software components be clearly linked with part of a required computing element helped address this issue. For example, a script that carries out some function should be shown as part of a corresponding laptop or server block.

One of the challenges specific to our domain of electrical and computer engineering is it that contains elements of both electrical engineering and computer science. Each of these domains, separately, have a number of established design processes and representations some of which are effective in the other discipline and others which are not as effective. We have attempted to integrate these processes as much as possible to keep the students from having to carry out two completely separate processes, however this has proven to be challenging. An area that needs significantly more work is to better integrate the use case diagram which represents dynamic processes such as flow and function with the block diagram which captures static structure. Of all the representations presented these two are most central to the project and used most by student teams. 
Annotated Mind Map (1:D-E): The annotated mind map is also used to capture high level elements of system performance and needed resources. Students are given an initial mind map to represent their project with the four elements shown below in figure 4(a): performance, function, form and system. The Function and Performance boxes seed research in to how the design team will define and measure the performance of the project, which in turn depends on what functions they seek to implement. This research informs "how the system works" or development of the use case diagrams. The System and Form boxes relate to the question "what exactly are we building" and this research informs development of the block diagram. A typical mind map near the end of the validation phase, which captures the team's research is shown in Figure 4(b). While too small to read, the individual boxes have links to annotations.

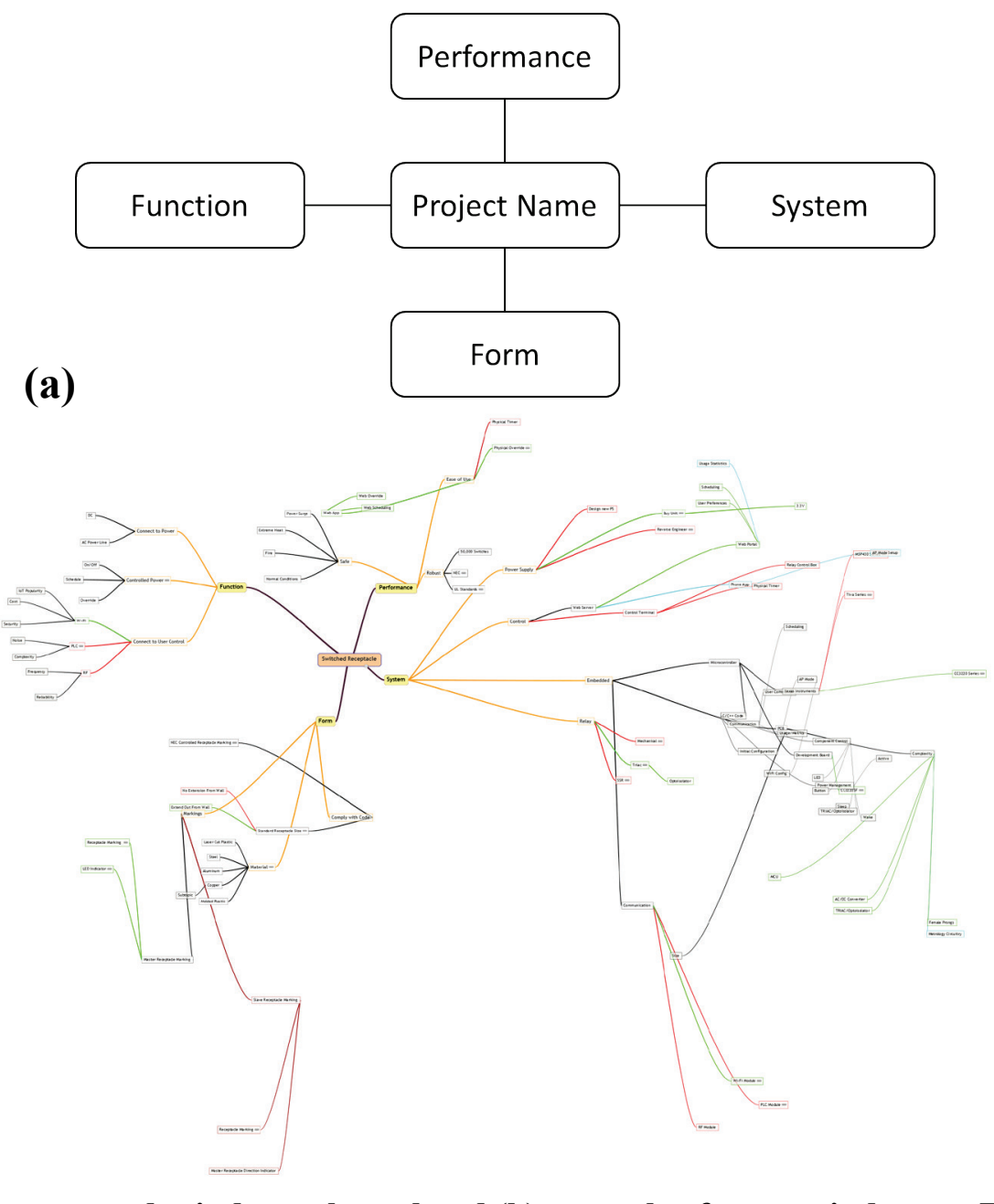

Figure 4: Initial annotated mind map kernel and (b) example of team mind map. The initial four branch kernel can be seen in orange and yellow in the center of the diagram.

Metrics, Tests, and Data (2-4:D): To focus student attention on the need for verification during the validation phase, teams are asked to develop metrics, tests, and capture data on the 
performance of their system and subsystems. Metrics are used to refer to a systemic process that lays out what and how a device or a system should be tested to provide evidence for some claim. The metrics are presented as a logical train of thought (if switch A is flipped light B comes on) that verifies what the team thinks should happen actually does. Tests are specific actions a student or team takes to determine if the design or subsystem they created performs as it is supposed to and are usually represented as a set of instructions (hook this up, run that, measure this) that make the result repeatable. Tests are used to confirm metrics, or provide the proof a system functions. Data is used generically as the information acquired during a test that is used to support claims in the metric after it has been properly analyzed and presented.

While conceptually simple in practice this has been an area in which student performance lags instructor expectations. One recurring issue is that students often focus on yes / no or work / not work forms of tests rather than trying to measure the performance level of project functions. Students often have difficulty selecting metrics that are relevant to overall project performance as well. Finding better ways for students to think through the metrics, tests, and data they need to collect and tie it to functional (use case diagrams) and architectural (block diagram) representations is an ongoing issue. We hypothesize this issue arises because little time is spent in pre-requisite courses on system performance since most student effort is focused on achieving a given function, i.e. getting something to work. Our observations suggest that performance only becomes relevant when students iterate multiple times on an assignment or project which is often difficult to achieve in typical curricula.

Project Logistics - Work Breakdown Structure, Critical Path Model, etc. (2:E): The relationship between system function and project resources (time, money, expertise) is expressed through project management and logistic representations. Each team has a dedicated project manager who is responsible for project logistics. The project manager can choose from a variety of project representations including work breakdown structures, Gantt charts, critical path models, or burn down charts. Work breakdown structures tend to be popular to identify tasks which are then coupled with Gantt charts to keep track of time.

Basecamp Updates (3-4:E) To keep track of project logistics and interactions at the detailed levels of design students are required to post updates to Basecamp [27] at least once per week. Basecamp is a popular project management web service that provides a private, secure space online where people working together can organize files and contribute to discussion threads. In Several different methods of keeping track of project evolution were explored during the action research phase with Basecamp proving to balance ease of use with completeness. While students initially resented making weekly Basecamp posts since they did not see these as germane to the design project, there is increasing acceptance and perception of value over time. The two instructors comment on student posts at least weekly so that students received regular feedback on their progress. Basecamp was very valuable to the course instructors since it provided regular insights into team progress. 
As described previously this paper presents a multi-year, holistic attempt to create improvements in the outcomes of a capstone design course through changing the way the course is structured. For this reason the paper does not intend to promote easy fixes or readily adoptable course modules or practices. Rather the assertion is that through regular adjustments in a course made over multiple years and supported by extensive student feedback desired course outcomes can be improved, in this case student's ability to represent design processes. While it is not possible to completely disentangle one practice from the larger effort, the instructors have made observational judgments on the types of representations that were more effective in achieving course goals. The three most successful representations - defined loosely by the ratio of benefit for achieving course goals to the difficulty of implementation-have been hypothesis testing using interviews, block diagrams, and Basecamp with interviews being by far the most successful. Note that any of these techniques requires proper scaffolding. For example since some students have a high level of stress at the prospect of conducting interviews, the topic is introduced in class by having a faculty member who performs stand-up comedy come in and conduct a session on how to do improvisational comedy.

In the second tier of effectiveness are annotated mind maps since they have begun to address a perennial issue of students not conducting sufficient research. Similarly use case diagrams and logistic models are still undergoing considerable adaptation in the action research cycle, but have improved over time. The other representations are useful but not as impactful in the overall design process as those mentioned above. As mentioned previously and shown in Figure 3 students are required to use hand-drawn representations on large sheets of paper until the start of the verification phase. Our experience is that hand drawn representations actually support more frequent revisions and thus support more rapid iteration of team designs.

Overall, creating physical representations of the design process has been successful at improving students understanding of the design process as well as delaying mental commitments to a particular design choice and the desire to converge too quickly.

\section{Using the Design Canvas in a capstone course}

In implementing the Design Canvas the instructors had to choose whether to introduce the canvas all at once to provide an overview of the design process or introduce various elements over time. Because the overall canvas and number of representations could potentially be somewhat overwhelming, the second approach was used by introducing representations in three consecutive project milestones. The staged introduction format also allowed time for students to iterate earlier representations. To support the staged introduction the validation phase (first semester of the capstone sequence) was divided into six consecutive milestones, shown in Figure 5. The first two milestones were only one week in length and focused on introducing students to the projects and team formation and development. The design canvas representations were introduced sequentially over the third to fifth milestones. The intensity of the shading of the boxes in Figure 3 represents the order of introduction with lighter boxes being introduced in milestone three, the next darkest in the fourth, and the darkest shades boxes in the fifth 
milestone. The form of the representations was introduced at the start of a milestone and the representations were due at the end of the milestone along with student presentations to put the representations in the perspective of their project. Iterations of previously produced representations were also due in later milestones. Mapping the representations in shaded boxes in Figure 3 to the test Vee of Figure 1 it can be seen the order of introduction generally follows the Vee model.

The third milestone, the first where representations are due, focuses on developing a high level view of the project and identifying stakeholders and their needs. Milestone four has students represent their first iteration of the project structure or architecture and identify project functions and performance metrics. In the fifth milestone student teams assign subsystems to individuals who then create representations of their block(s) function. While instructors purposely take a very hands-off approach for most of the semester to let customer interviews drive the form and direction of the teams' design at the end of the fifth milestone a formal SWOT analysis is used to give direct feedback to teams. The final milestone of the validation phase is to do a final iteration of all the representations and present their evolution over the course of the semester. Discussing how the representations and teams' view of the design project changed over the course of the semester is part of the presentation in the sixth milestone. Students are also asked for individual written reflections at this point in time and an after action review is conducted during the course's schedule exam time.

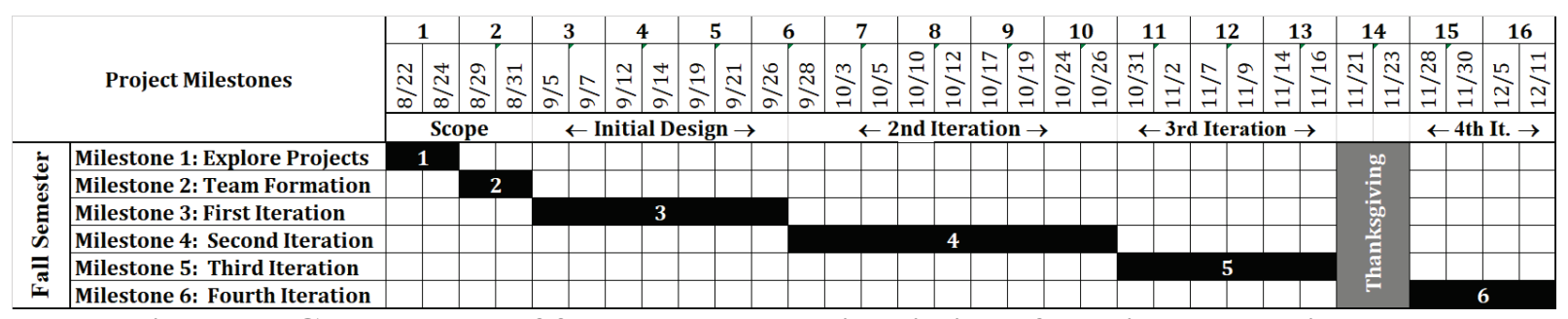

Figure 5: Gantt charge of fall semester showing timing of the six course milestones

While this article focuses on representation creation in the validation phase, the created representations are used in the spring semester when the teams work back up the test Vee during the verification phase. We have observed that once students start to dive into the details of project development the representations created in the validation phase can be quickly forgotten. To keep attention on the overall process the unit, integration, and assessment tests (see figure 1) are framed by how well they match validation phase representations. Teams are encouraged to update their representations, but must discuss the rationale for doing so as part of the milestone presentations.

All milestone presentations adopt different formats to give students a range of experiences in communication. To evaluate the representations the instructors use rubrics mapped to ABET outcomes. These rubrics provide a relatively easy way to both assess student work but also to look at changes in the quality of the representation over the course of a semester. To date rubrics have focused on the representations based on the underlying assumption that representations are 
the project. However the latest student after action review indicated that students see the representations as somewhat separated from the project because of the lack of hardware and/or software so a future task is to modify the rubrics to focus more on the design choices made during development of the project as communicated through the representations rather than on the representations themselves.

\section{Lessons, successes, and failures}

During the multi-year action research project the authors have gained several insights into the effectiveness of using design representations that capture process as products during a capstone course. It is worth stating that the reported use of representations was not a short, discrete intervention in a capstone course but rather constituted a fairly significant restructuring of the course based on action research. For this reason it is difficult to frame observations and analysis of available data to draw better vs. worse conclusions. Rather it is more appropriate to discuss broad changes in student learning and course outcomes that arose from the intentional restructuring. As discussed at the start of the paper there were several goals that introducing representations sought to address. These included: improving student understanding of the relationship between design process and the resulting product; emphasizing the relationships between form and function specifically with regards to iterative improvements in performance; understanding how creating design representations serve to make design a more social process through centering conversations and negotiations on shared artifacts; and understanding that spending time working with clients and users in the early, divergent phases of design rather than rushing to a technological solution helps to create value.

In comparing how students' understanding of the relationship between product and process changes one observation is that utilizing representations helped to structure and scaffold the design process for both students and faculty. On the faculty side the process of regular meetings in which student feedback was reviewed stimulated ideas on how to help students formally represent the design process. Developing or adapting representations that captured both the product and process and map these to the design canvas provided considerable guidance on when to present material and how to prompt students to shift between convergent and divergent thinking [5]. On the student side instructors observed students used the representations in their conversations on a regular basis, likely because of the strong emphasis on reporting through representations. As representation became more central to progress reporting it became easier for faculty to gain insights into the process which student teams used iterate their design since changes to earlier representations were discussed in presentations of later milestones. Furthermore the fact that student teams were required to keep archival paper copies of each iteration enabled these to be laid out in temporal sequence to have discussions around the changes over time and what aspects of the design process drove those changes. The process of iteration and changes in teams' understanding of how the product created has evolved over multiple iterations is clearly evidenced by the archive of representations collected over the project. 
Another way the relationship between product and process changed was to shift attention away from product development to the process. We have observed that by focusing on creating representations as artifacts most students hold off on making premature decisions about how to implement the design and are willing to spend more time in project scoping. Making early decisions about the pathway to a solution is an indicator of design novices [17]. A factor that contributes to this delay in committing to a design is having student teams first focus on the larger context of their design project in milestone \#3. By holding off on moving down the rows of the design canvas, Figure 3, until later in the semester students are not introduced to representations which allow detailed design to take place.

There were two observed changes in student understanding of the relationships between form (e.g. structure or architecture) and function and how these evolved through iteration. The first was that focusing on representations as a product during the validation phase of the capstone project helped to develop abilities in abstracting problems. Abstraction is a key skill in electrical and computer engineering given the truism that "my system is your component". Being able to abstract function is a needed ability for system development, and was one of the desired outcomes that drove the structural changes to the capstone course. Analysis of the evolution of representations and student descriptions over multiple iterations show that abilities to abstract increased by introducing representations. However students still had difficulty consistently abstracting function and tended to revert to the detail-oriented perspective which more traditional content-focused classes and labs supported without continual prompting. The authors also see some evidence that students' ability to abstract increased through the form of dialog when discussing the projects as well as iterative improvements in the representations which focused on project function. The level of understanding is variable from team to team however and work is needed to better develop students' abilities in abstraction and system engineering.

One area in which focusing on design representations has not been as successful as desired in relating form and function is to develop student understanding of the complicated relationship between project architecture (which is static) to project function and performance (which are dynamic and sequential). One area in which the instructors iterated the form of representations based on student feedback was to develop or adopt a representation that captures function in a way that is simple and intuitive enough for students to grasp quickly yet can capture the level detail needed to express function. Early attempts to use multiple representations for function proved overwhelming for students and the representations were not well aligned with each other which may have contributed to misunderstandings. Currently modified use case diagrams are being used which are somewhat successful.

An area related to function and performance in which more work is needed is how to represent metrics, tests, and data. We have observed that most students have difficulty conceiving of system or subsystem performance measures and tend to focus on tasks focused more on debugging rather than performance characterization. It is hypothesized that this form of testing is emphasized in lab experiences that occur earlier in the curriculum. The forms of representations we have developed to date do not sufficiently scaffold issues of system 
performance. Considerably more work is needed to develop a set of representations that connect the structure or architecture of a project with its function, and the way the performance of the function and architecture are measured.

In terms of the goal of understanding how creating design representations serve to make design a more social process we have observed through both formal meeting and Basecamp that the way students communicate outcomes of their project have changed due to changes in reporting requirements. This is not surprising since the structural changes to the course were designed to support communication and negotiation. Because representations are developed sequentially and iterated over time as well as supported by regular (at least weekly) posts to Basecamp project reporting is more evenly distributed over the entire year. This structure was successful in both making discussions regular and ongoing, as well as making them more transparent and open to instructor feedback. In earlier iterations of the course project documentation was more haphazard and tended to be concentrated in the final month as report deadlines approached. It has been difficult to structure such continuous reporting for several reasons. One is simply to understand the time requirements on students. Another is due to resistance from some students because they believe reporting results before the end of the project can be a waste of their time. More work is needed to develop and support more regular communication in the capstone course.

An area related to design as a social process that has had more mixed results is the extent to which representations, and to a lesser extent the design canvas, became centers of conversation. While a desired outcome was to have students use abstract representations of their project as centers of negotiation [12], too often the conversation focused on what was "right" or what was needed to satisfy the instructor or achieve an acceptable score on reports using the representations. In other words rather than see representations as valuable tools to support the design process they are seen as reporting requirements. In some students view the focus on representation could be seen to detract from a team's focus on the project itself. As discussed previously recent conversations with students have suggested that adjusting the rubrics to focus less on the representations as artifact and more on representation as abstraction may allow this issue to be somewhat mitigated.

There have been very positive shifts over time in getting students to adopt more of a humancentered design approach where a project takes direction clients and users rather than faculty before jumping into convergent, technical design. The most successful element to holding off on locking down the direction of the design are having students conduct user interviews. In this course as in others it was difficult for the instructors to determine how active they should be in setting design directions for students. Too much feedback resulted in having students simply follow faculty instructions which interfered in developing student ownership of the project. On the other hand providing too little guidance contributed to an environment in which some teams floundered when tackling aspects of the project they were unfamiliar with which undermined team motivation. Getting regular feedback from clients, users, and customers through a hypothesis-driven interview process allows feedback on teams' design by using the relatively 
low-investment representations as centers of conversation. As a result we have observed more of a willingness for teams to pivot (shift project direction) if the project is drifting away from meeting client needs.

\section{References}

[1] S. Howe, S. L. Poulos, and L. M. Rosenbauer, "The 2015 Capstone Design Survey: Observations from the Front Lines," in ASEE Ann. Conf and Exhib., 2016.

[2] L. J. McKenzie, M. S. Trevisan, D. C. Davis, and S. W. Beyerlain, "Capstone Design Coures and Assessment: A National Study," ASEE Ann. Conf. and Expos. Salt Lake City, 2004.

[3] D. Davis, S. Beyerlein, O. Harrison, P. Thompson, M. Trevisan, and B. Mount, "A conceptual model for capstone engineering design performance and assessment," Proc. 2006 Am. Soc. Eng. Educ. Annu. Conf. Expo., 2006.

[4] A. J. Dutson, R. H. Todd, S. P. Magelby, and C. D. Sorenson, "A Review of Literature on Teaching Engineering Design Through Project-Oriented Capstone Courses," J. Eng. Educ., vol. 86, no. 1, pp. 17-28, 1997.

[5] C. L. Dym, A. M. Agogino, O. Eris, D. D. Frey, and L. J. Leifer, "Engineering Design Thinking, Teaching, and Learning," J. Eng. Educ., vol. 94, p. 103, 2005.

[6] L. Bucciarelli, Designing Engineers. Cambridge, MA: The MIT Press , 1996.

[7] A. Acuna and R. Sosa, "The Complementary Role of Representations in Design Creativity: Sketches and Models," Proc. Int. Conf. Design and Creativity. Japan, 2010.

[8] M. Lande and L. Leifer, "Work in progress - Student representations and conceptions of design and engineering," in Proceedings - Frontiers in Education Conference, FIE, 2009.

[9] B. Davidowitz, G. Chittleborough, M. Representations, and I. N. Chemical, Multiple Representations in Chemical Education, vol. 4. 2009.

[10] T. J. Moore, R. L. Miller, R. A. Lesh, M. S. Stohlmann, and Y. R. Kim, "Modeling in engineering: the role of represntational fluency in students' conceptual understanding," $J$. Eng. Educ., vol. 102, no. 1, pp. 141-178, 2013.

[11] J. Krupczak and G. Bassett, "Work in progress: Abstraction as a vector: Distinguishing engineering and science," in Proceedings - Frontiers in Education Conference, FIE, 2012.

[12] B. J. Kallenberg, By Design: Ethics, Theology, and the Practice of Engineering. Eugene, Oregon: Cascade Books, 2013.

[13] C. Haskins, K. Forsberg, M. Krueger, D. Walden, and D. Hamelin, "Systems engineering handbook," in INCOSE, 2006.

[14] G. M. Bodner and M. Orgill, Theoretical Frameworks for Research in Chemistry/Science Education. New York: Prentice-Hall, 2007.

[15] Cheville, "Transformative Experiences: Scaffolding Design Learning Through the Vygotsky Cycle," Int. J. Eng. Educ., 2010.

[16] R. Harre, Personal Being. Cambridge, MA: Harvard University Press, 1984.

[17] J. W. Creswell, Research Design: Qualitative, Quantitative, and Mixed Methods Approaches. Thousand Oaks: Sage, 2003.

[18] M. Polyani, The Tacit Dimension. Garden City, NY: Doubleday \& Co., 1966.

[19] M. Simoni, E. Andrigcic, and W. A. Kline, "Integrating Systems Competencies into the Curriculum of Any Engineering Discipline," in ASEE Ann. Conf and Exhib., 2015.

[20] C. Hixson, W. A. Kline, J. Ahmad, R. D. Rogge, and R. M. Bunch, "Teaching with the 
Innovation Canvas: A tool for value-driven, integrated design education," in ASEE Ann. Conf and Exhib., 2014.

[21] W. A. Kline et al., "The innovation canvas - A tool to develop integrated product designs and business models," 120th ASEE Annu. Conf. Expo., 2013.

[22] R. M. Ford and C. S. Coulston, Design for Electrical and Computer Engineers. New York: McGraw-Hill, 2007.

[23] J. A. Marin, J. E. Armstrong, and J. L. Kays, "Elements of an Optimal Capstone Design Experience," J. Eng. Educ., vol. 88, no. 19-22, 1999.

[24] A. Osterwalder and Y. Pigneur, "Business Model Generation - Canvas," Wiley, p. 280, 2010.

[25] S. Blank and B. Dorf, The Startup Owner's Manual: The Step-By-Step Guide for Building a Great Company. Pescadero, CA: K \& S Ranch, 2012.

[26] G. Constable, Talking to Humans. Self published, 2014.

[27] R. Featherstone, "Basecamp: Tech Review," J Med Libr Assoc, vol. 97, no. 1, p. 67, 2009. 